\title{
FDA to oversee reporting of clinical trials
}

The US Food \& Drug

Administration (FDA)

is newly responsible for ensuring that companies

report clinical trials

correctly in the ClinicalTrials.gov registry. The US Health and Human Services

Secretary, Kathleen Sebelius, on September 5 charged the FDA with monitoring the database. The FDA will now determine whether any clinical trial information logged in ClinicalTrials.gov is complete and accurate, as required by law, or is false or misleading.

The job of registering all trials and checking up on unreported results will pose a considerable challenge to agency officials. An analysis published in May (J. Am. Med. Assoc. 307, 1838-1847, 2012) of the characteristics of clinical trials registered in ClinicalTrials.gov "raises questions about the best methods for generating evidence, as well as the capacity of the clinical trials enterprise to supply sufficient amounts of high-quality evidence needed to ensure confidence in guideline recommendations." The analysis was conducted by the Clinical Trials Transformation Initiative (CTTI), a public-private partnership founded by the FDA and the Duke Translational Medicine Initiative. First author Rob Califf, of the Duke Translational Medicine Institute of Durham, North Carolina, says new features introduced with recent FDA reauthorizations are oriented toward providing more transparency in the clinical trials enterprise, "But more can be done," he says.

Past efforts to move industry into greater compliance with the aims of ClinicalTrials. gov have fallen short. In 2004, the New York State Attorney General sued Londonbased GlaxoSmithKline (GSK) for failing to reveal unfavorable results from trials of its antidepressant Paxil (paroxetine) in children (the case was settled). That same year, the International Committee of Medical Journal Editors said its members' journals would not publish reports of trials unless they had been registered in ClinicalTrials. gov - a policy that apparently has been only poorly implemented.

In Europe, the European Medicines Agency and the heads of the Dutch, French and UK drug regulators called in mid-April for raw data from clinical trials to be made publicly available (Nat. Biotechnol. 30, 371, 2012). The plea for openness followed a publication in PLoS Medicine (9, e1001201, 2012) of a Cochrane Review on Roche's approved influenza drug Tamiflu (oseltamivir). The researchers undertaking the metaanalysis cited multiple difficulties in obtaining the clinical data for the neuraminidase inhibitor from the Basel-based pharma.

As regulators tighten up on clinical trial reporting, GSK has taken a transparency vow. CEO Andrew Witty said on October 11 that the company will create a system to allow researchers access to detailed de-identified patient data from clinical trials. The initiative, which includes GSK's approved and discontinued investigational medicines, is a step toward developing a broader system enabling the clinical research community to access data from clinical trials conducted by different sponsors. "GSK hopes the experience gained through this initiative will be of value in developing and catalyzing this wider approach," the company announced at a meeting hosted by the Wellcome Trust in London. In the past, GSK has been criticized for a lack of transparency in making side effects publicly known, as was the case for the diabetes drug Avandia (rosiglitazone), resulting in the drug giant paying a $\$ 3$ billion settlement.

With GSK's announcement also came the launch of an initiative called Project Data Sphere that is designed to provide a shared platform through which historical clinical trial data will become available to researchers. This collaborative effort stems from the nonprofit organization CEO Roundtable on Cancer (of which GSK is a member), whose Life Sciences Consortium set up a task force to accelerate research and development in oncology. "Broadly sharing existing clinical trial data for the benefit of all researchers can be a key driver in speeding up cancer research efforts, encouraging innovation and honoring those patients who have participated in clinical trials as well as those future patients who deserve our very best collective efforts in discovering new and better therapies," says Roundtable chairman Chris Viehbacher, CEO of Parisbased drugmaker Sanofi. 